\title{
White Conceptions of Racial Hierarchy: Temporary versus Permanent Preferences
}

\author{
Jonathan Gayles \\ Sarah Tobin
}

\section{Georgia State University}

\section{Studying Hierarchy}

Ideas of race, racial identity, and racial categorization, reflect the inconsistent, context-specific and fluctuating nature of racial meaning (Nagel, 1986; Forbes, 1990; Davis, 1991; Nagel, 1994; Haney-Lopez, 1995; Ignatiev, 1995; Kibria, 1996,1998; Niven \& Zilber, 2000; Morning, 2001; Lacy, 2004). Studies of racial hierarchy, specifically, enable an understanding of not only the social construction of race, but also the manner in which ideas of race operate to influence human reality. 1 Within the United States, race "permeates the lives of the native-born and immigrants alike" (Bashi \& McDaniel, 1997, p. 686, see also Bashi, 1998). More specifically, a continuum between white and black persists and is a critical conceptual schema grounding the many manifestations of racism in the United States. This white-to-black continuum is hierarchical as well with whites at the top and blacks at the bottom (Feagin, 2000, p. 220). While the specific history of the United States facilitates this hierarchy, it has also been found beyond the borders of the United States (Small, 1994, Twine, 1998).

Further framing this white-to-black hierarchy is the assertion that some 
groups are neither white nor black, yet fill an intermediary space that entrenches the opposition of the two poles between which they are placed (see Almaguer, 1994 for a historical treatment of this topic). An excellent example of this situating is the research regarding the unique or even "model minority" status attributed to Asian-Americans (Chae, 2004; Edles, 2004; Ho, 2003; Tuan, 1998; Yamato, 1999). Min (1999) explicates the origins of much of this research as follows:

In the 1970s, the U.S. media and many scholars portrayed Asian-Americans as successful minority groups that overcame disadvantages through hard work, family ties, and emphasis on children's education. Largely in reaction to this "model minority" thesis, Asian-American scholars began to emphasize the structural barriers facing Asian-Americans. The revisionist critique of the model minority thesis currently has a powerful influence in Asian-American scholarship (195).

This "revisionist critique" critically engages the reductionist, monolithic and de-contextualized construction of the model minority and presents a more complete understanding of dynamic Asian-American experiences in the midst of racial group struggles. Lee (1994) for example, suggests that the representation of the model minority is not static, and represents a complex combination of contextual influences in the schooling experience of Asian American youth.

Arab-Americans provide another example of an emergent intermediary group. Particularly visible since September 11, 2001, Arab-Americans have come to the fore of race relations in a politically charged atmosphere. As Domke et. al (2003) describe, post September 11, 2001 representations in the popular and mass media outlets may have reproduced racial hierarchy in the United States and worked to support a position endorsing racial profiling. They found that prior to September 11, 2001, "policing" was a primary focus of news coverage on racial profiling, and constituted $82 \%$ of the discourse on the topic. After September 11, 2001, however, "terrorism" and "policing" occupied 95\% of the racial profiling discourse. Their results indicate that while white Americans are more likely to speak on racial profiling from positions of social power or leadership than African-Americans or Arab-Americans, the post- September 11, 2001, discourse granted Arab-Americans a relatively higher and more powerful position to speak on the topic than African-Americans have historically been granted. Ultimately, the location of whites at the top of the hierarchy remains untouched while other racial groups, specifically Arab-Americans and African-Americans, compete for much lesser positions of authority.

Scholarship on racial hierarchy extends the boundaries of national dialogue regarding race beyond the binary constraints of black and white. In a scathing critique of binary constructions of race, Forbes asserts that such constructions reflect "an erroneous construction based upon an ahistorical acceptance of late 
nineteenth and twentieth-century generalizations and terminology" (1990, p. 12). Although "erroneous," the singular and unique experiences of members of groups that are neither singularly black nor white are important to our understanding of the multifaceted reality in which we live. Feagin suggests that white-on-black oppression is definitive for everyone in the United States. It is, he states:

a comprehensive system of exploitation and oppression originally designed by white Americans for black Americans, a system of racism that for centuries has penetrated every major area of American society and thus shaped the lives of every American, black and nonblack (2000, p.204).

Consistent with Feagin's argument, while it is important to pursue an expanded conception of human diversity, we must also recognize the persistent and current consequences of present-day conceptions of race.

Recent research on whiteness extends our understanding of these consequences in an important way for it reveals whiteness as a coherent racial reality critical to the maintenance of systems of white domination (Igantiev, 1995; Sleeter, 1995; Giroux, 1997; Lipsitz, 1998; Roediger, 2004). The implications of this research further reveal that racial hierarchies situating whites at the top represent more than simply a specific historical outcome. Rather, these hierarchies represent ongoing participation by white people in systems of privilege that solidify their position at the top of these hierarchies.

Although there is an abundance of research addressing racial hierarchy in its manifestations as racial inequity and inequality, "there is little discussion of what exactly racial hierarchies are and how they operate" (Song, 2004, p. 860) although social dominance theory has served as a theoretical lens through which racial hierarchy is examined. Social dominance theory focuses on both individual and structural factors that contribute to various forms of group-based oppression (Sidanius, 1993; Sidanius \& Pratto, 2001, Sidanius et al, 2004). A key explanatory component of this theory is behavioral asymmetry which asserts that more powerful members of society are inclined to act in their own interest more than the less powerful do. The construct of social dominance orientation reflects the tendency of the group to desire group-based domination (Sidanius \& Pratto, 2001).

Other scholars question the utility of social dominance theory in examining social hierarchy (Schmitt, Branscombe \& Kappen, 2003; Turner \& Reynolds, 2003; Wilson \& Lui, 2003). In particular, Turner and Reynolds (2003) assert that behavioral assymetry cannot be supported empirically and that social identity theory is more useful in explaining the response of subordinate groups to inferior positions on social hierarchies. Social identity theory (Turner, 1982; Tajfe $\&$ Turner, 1986) focuses on the meaning derived from group membership and the 
manner in which this membership influences relations with, and perceptions of, nonmembers.

Examinations of racial hierarchy are also present in research on racial intermarriage. The work of anthropologist Kingsley Davis (1941) examines patterns of intermarriage in societies that maintain racial and non-racial stratification. His comparative analysis serves as the genesis of what came to be known as the status exchange hypothesis. This hypothesis suggests that groups holding lower positions on the hierarchy compensate higher-position spouses with resources valued in that society. In this sense, a status exchange occurs as one spouse marries someone with a higher racial or ethnic status and the partner spouse marries someone that possesses additional resources (i.e. education). In an "improved" test of the status exchange hypothesis, Vincent Fu found support for the status exchange hypothesis in marriages between whites and blacks and between whites and Mexican Americans. In short, Fu found that "in a sphere of social interaction as intimate as marriage, racial stratification still is present for blacks and Mexican Americans; racial boundaries reduce their attractiveness to potential spouses" (2001, p. 157). That such "boundaries" were not as apparent between whites and Japanese Americans indicates that conceptions of racial hierarchy influence marriage patterns as well.2

While distinctions can be made between these theoretical orientations, neither theory is inconsistent with the widely accepted notion that race is socially constructed. Much convincing scholarship indicates that it is not only useless to attempt to divide humanity into discrete biological categories based on skin color; it is impossible (Montagu, 1942; Gould, 1981; Graves, 2003, 2004). Further, some authors assert that the continued use of static racial categories reify these categories and the hierarchies that they imply (Forbes, 1990; Verkuyten, Masson \& Elffers, 1995). The implication of such assertions is that racial categories "must be totally discarded as part of the process of personal and popular liberation they must also be pruned away from scholarship" (Forbes, 1990, p. 36). The authors do not believe that the concept of race itself should be discarded in investigating racial hierarchies if for no other reason than the fact that ideas of race remain pertinent to human interaction. We, like Mukhopadhyay and Moses, feel that it is "naïve and empirically inaccurate to imagine a simple relationship between a belief in races and racial discrimination" (1997, p. 358). The study of racial hierarchy is valuable because it assists us in unraveling the nature of human interaction, not because race itself represents a valid scientific construct. Race is salient because humans make it salient. Its salience impacts our behaviors toward one another and therefore it is dangerous to discard it as a focus of research.

Research on racial hierarchy cannot be characterized by any one discipline, methodology or perspective. Racial hierarchy is both a result of historical 
circumstance and present-day interaction. It lends itself to biogenetic, cultural, political, economic, psychological, and mass media interpretations. No one theoretical framework is likely to offer a fully panoptic perspective of racial hierarchy. In an effort to contribute meaningfully to the understanding of racial hierarchy, the primary purpose of the research reported here is an empirical examination of attitudes of preference and aversion towards racial group membership, expressed racial hierarchy, and the implications of those choices by white students.

\section{Methodology}

The primary research problem that we investigate involves understanding the current, that is post-September 11, 2001, perceptions of racial hierarchy by white undergraduate students at the University of South Florida (USF). More specifically, this research seeks to examine temporary versus permanent patterns of preference and aversion among respondents. The results of this research reflect the current conceptions of racial hierarchy among the participants.

The research was guided by three primary hypotheses:

1. Given an opportunity to be a member of a racial group other than their own, black group membership will be the least preferred group in both temporary and permanent conditions.

2. Being forced to be a member of a racial group other than their own, black group membership will be the most aversive group in both temporary and permanent conditions.

3. The respondents will be less inclined to indicate "I have no preference" in the permanent conditions.

\section{The survey}

A survey was administered to 446 undergraduate students at the University of South Florida during the 2004 academic year. Respondents were students in five classrooms of lower-level Anthropology courses. Of the 446 respondents, 221, or 54, were self-identified as white. 100 of those respondents indicated that they were also categorized as white by others. This is important for consonance between self and other-identified white group membership increases the likelihood that their responses are indicative of their experiences as whites rather than the experiences of those who identify as white but do not necessarily experience the world in this way. 3 As we are primarily interested in connecting this research to the growing body of scholarship on whiteness and racial hierarchy, we focus exclusively on the responses of the white participants.

The available categories of race on the survey were generated by an 
Introduction to Anthropology class section that was not included in the research. When asked to free-list the racial categories they perceived, those with the highest aggregate counts were selected. As a result of this pilot test, and in conjunction with the most recent categories used by the United States census, 4 the following list of categories was used:

\begin{tabular}{|l|l|l|l|l|l|l|l|l|l|}
\hline \multicolumn{2}{|c|}{ TABLE 1: Available Responses } \\
\hline a) & Arab & d) & Black & g) & Native Am ericanAlaskan Native & j) & $\begin{array}{l}\text { I have no } \\
\text { preference }\end{array}$ \\
\hline
\end{tabular}

Although "Arab," “Asian Indian," "Hispanic," and "Jew" are not represented as separate racial categories in the U.S. census listing, they were frequently indicated as distinct racial categories by students in our pilot test. Although this research relies on recognizable racial categories, the categories used are informed by the participants instead of being limited by static and traditional conceptions of race (Verkuyten, Masson \& Elffers, 1995). To potentially assuage trepidation that respondents may have had regarding the limiting nature of these categories (as well as similar trepidation on behalf of the researchers), an explanatory caveat introduced the survey:

The racial categories used here, although limited, reflect a combination of the evolving categories used by the United States census and categories identified by other USF students. For matters of consistency, familiarity and simplicity, these terms are very general. Although the racial categories do not adequately capture the rich diversity that is found in the United States or in humanity, these categories provide us with an important reference point to examine attitudes on racial group membership in the United States.

Ultimately, of the 211 participants, 126 women and 85 men participated. Nearly all (204) of the participants indicated that they were born in the United States. Finally English was the first language of the overwhelming majority of the participants (194).

The survey consisted of sixteen questions. Twelve of the questions asked about conceptions of racial privilege and the perceived race of children of mixed racial heritage. The remaining four questions were demographic and asked for self-identified and ascribed racial categories. Of the sixteen questions on the survey, four of them are the focus of the research reported here. They include:

1. "If you had one opportunity to be a member of a racial group other than 
your own for a temporary period of time, returning to your own group when you wanted, which one of the groups from TABLE 1 would you most want to be? (Remember that you cannot choose your own group.)" 2. "If you had one opportunity to be a member of a racial group other than your own for a temporary period of time, returning to your own group when you wanted, which one of the groups from TABLE 1 would you least want to be for a temporary period of time? (Remember that you cannot choose your own group.)"

3. "If you were forced to be a member of a racial group other than your own permanently, never returning to your own group, which one of the groups from TABLE 1 would you most want to be? (Remember that you cannot choose your own group.)"

4. "If you were forced to be a member of a racial group other than your own permanently, never returning to your own group, which one of the groups from TABLE 1 would you least want to be permanently? (Remember that you cannot choose your own group.)"

\section{Results}

Figure 1: Temporary Preference

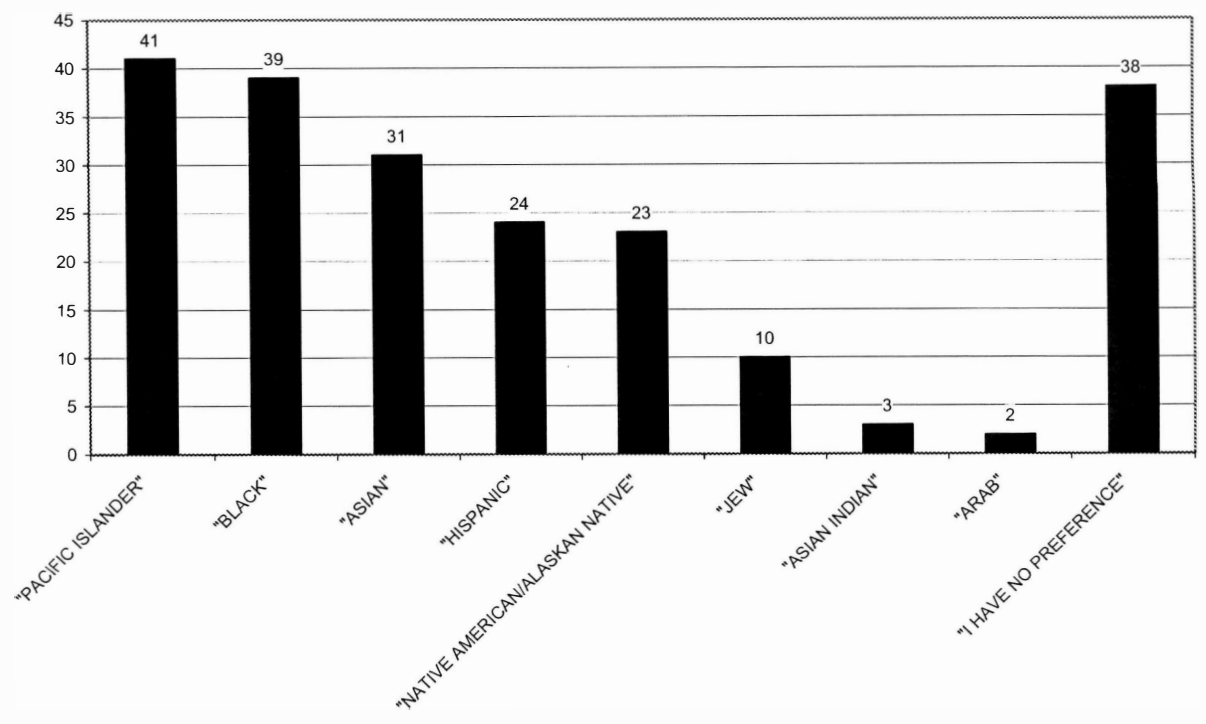




\section{Hypothesis One}

The first hypothesis, "Given an opportunity to be a member of a racial group other than their own, black group membership will be the least preferred group in both temporary and permanent conditions" is not supported. In terms of temporary group membership, Pacific Islander was the most preferred group $(n=41,19.43)$. Temporary preference for Pacific Islander was followed closely by temporary preference for black membership $(n=39,18.48)$. Clearly, the least preferred group is Arab group membership $(n=2, .95)$. Although there was a considerable preference for black group membership, we must not lose sight of the fact that this response reflects only the temporary condition. Still, the "temporary preference" portion of the first hypothesis clearly cannot be supported as temporary Arab group membership is the least preferred.

Figure 2: Permanent Preference

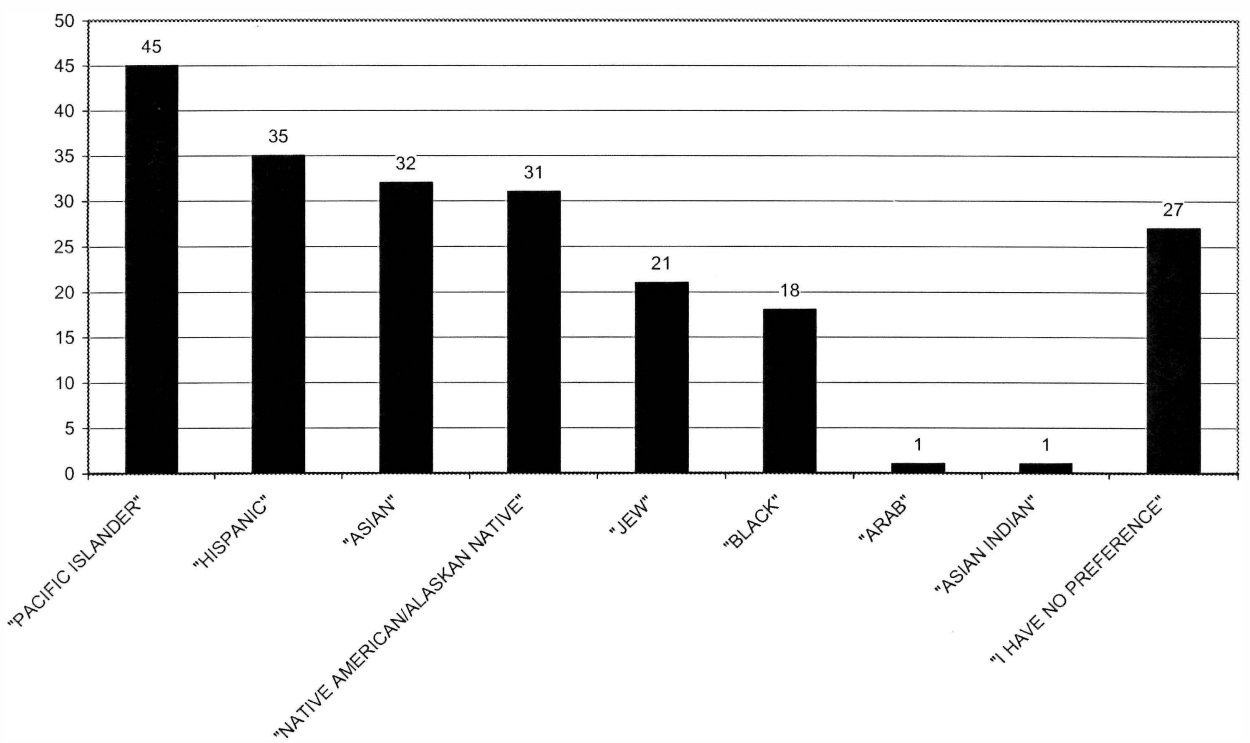

In response to the permanent condition for the first hypothesis, the results in Figure Two reveal some important differences. Pacific Islander membership is again the most preferred response and Arab group membership the least preferred although it is now matched by Asian Indian ( $n=1, .47)$. Temporary preference for black group membership no longer closely follows Pacific Islander, dropping from the second most selected racial group in the temporary condition to the sixth most selected racial group in the permanent condition. Despite this fact, the "permanent preference" portion of the first hypothesis also cannot be 
supported.

In order to more fully examine the differences between temporary and permanent preference, and further test the first hypothesis, it is necessary to compare the temporary and permanent preference responses. First, we note that Arab group membership was the least frequently selected response in both the temporary and permanent condition. Secondly, while temporary preference for black group membership nearly matched that of the most preferred group ( $\mathrm{Pa}$ cific Islanders; Figure 1), moving to the permanent condition reveals a severely negative impact on the selection of black group membership. The decrease in the percentage of white students indicating a preference for black group membership in the permanent versus the temporary condition (-9.95) was more than ten times the nearest such decrease. Figure 3 illustrates this change. From a descriptive perspective, moving from the temporary to the permanent condition had the most impact on the expression of preference for black group membership, and this impact was clearly negative. While these results still do not confirm the first hypothesis, the impact of moving from temporary to permanent on the selection of black group membership has implications for the interpretation of the results.

Figure 3:

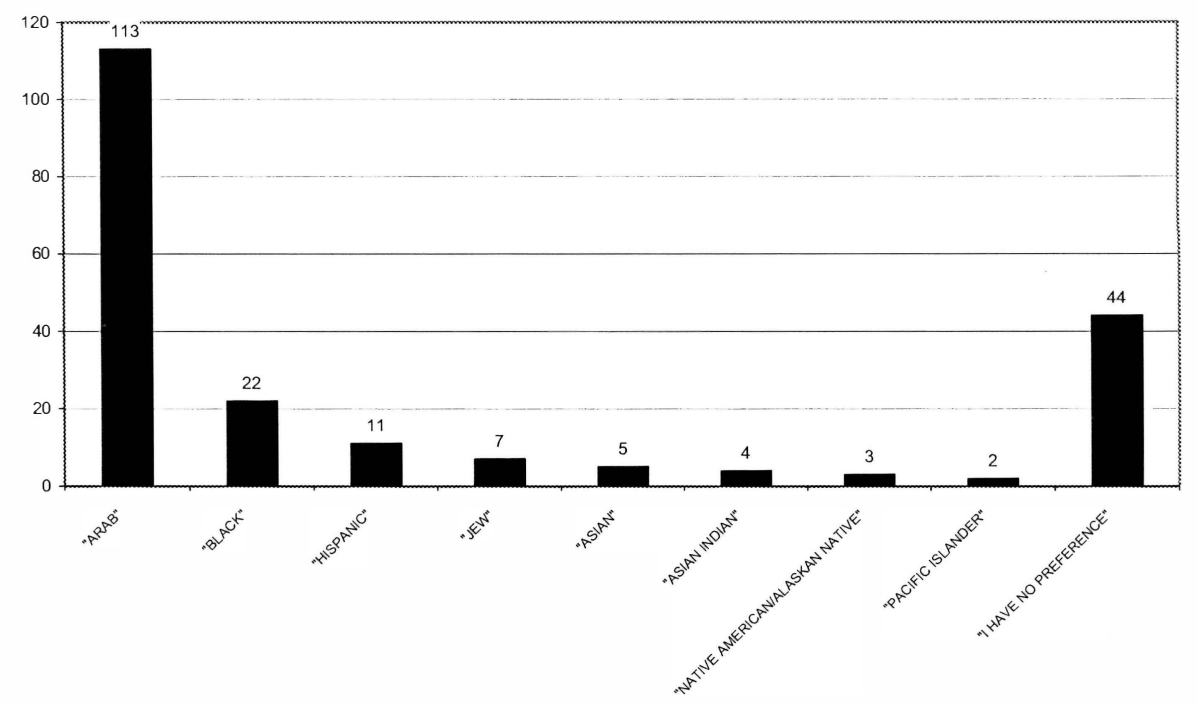




\section{Hypothesis Two}

The second hypothesis, "Being forced to be a member of a racial group other than their own, black group membership will be the most aversive group in both temporary and permanent conditions" is also not supported. The percentages of responses that were given for each answer are demonstrated in Figure 4: Temporary Aversion.

Figure 4: Temporary Aversion

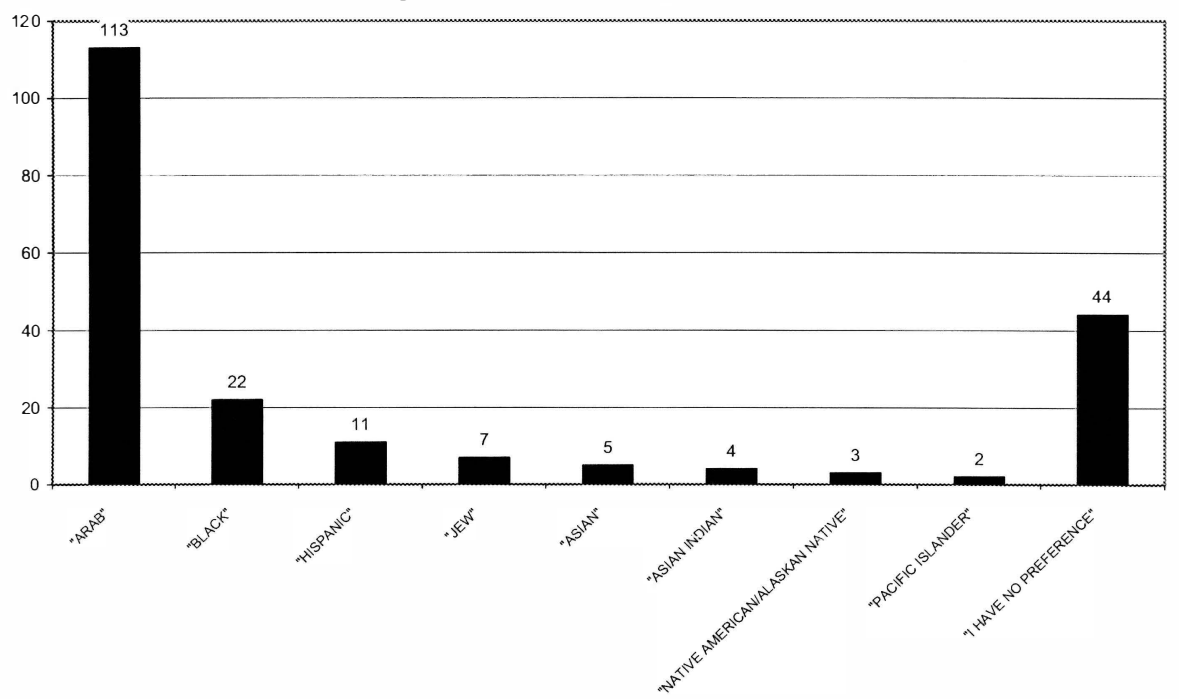

When forced to become a member of another racial group for a temporary period of time, respondents were overwhelmingly averse to temporary Arab group membership ( $n=113,53.55)$. In fact this aversion is more than five times that of the next most frequently selected group, which is black group membership ( $n=22,10.43$ ). The remaining selections of racial groups for this question are nominal. This distinguishes Arab and black as the two most aversive racial groups, with Arab group membership as the considerably more aversive of the two. Therefore, the second hypothesis that black group membership will be the most aversive of all the racial categories, or the "temporary aversion" portion of the second hypothesis, is not supported. 
Figure 5:

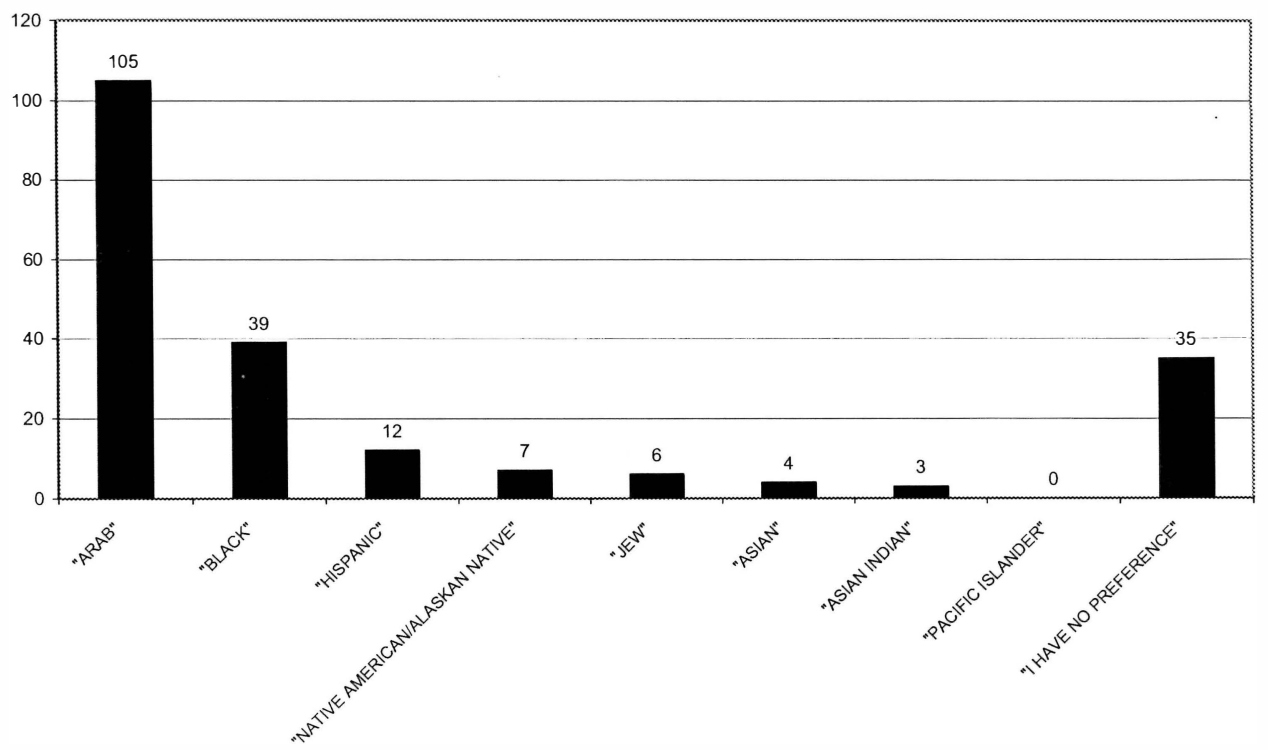

In the permanent condition, the percentage of respondents indicating that they were averse to permanent Arab group membership decreased as compared to the temporary condition (from $n=113,53.55$ to $n=105,49.76$ ) while the percentage of respondents expressing aversion to permanent black group membership increased as compared to the temporary condition (from $n=22,10.43$ to $n=$ $39,18.8$. In a similar manner to the temporary condition, moving to the permanent condition reveals Arab and black group membership as the most aversive. Still, these results also fail to confirm the second hypothesis that black group membership would be the most aversive.

As with the preference questions, an important pattern is revealed when comparing the temporary and permanent conditions for aversion. Figure 6 illustrates the change in responses when moving from the temporary to the permanent condition. The increase in aversion to black group membership when moving from the temporary to the permanent condition is the largest increase for any racial group (15.17). It is nearly five times the nearest increase (Hispanic, 3.32). Again, the second hypothesis that black group membership would be the most aversive choice cannot be confirmed but the results of the comparison necessitate further consideration. 
Figure 6: Temporary to Permanent Aversion

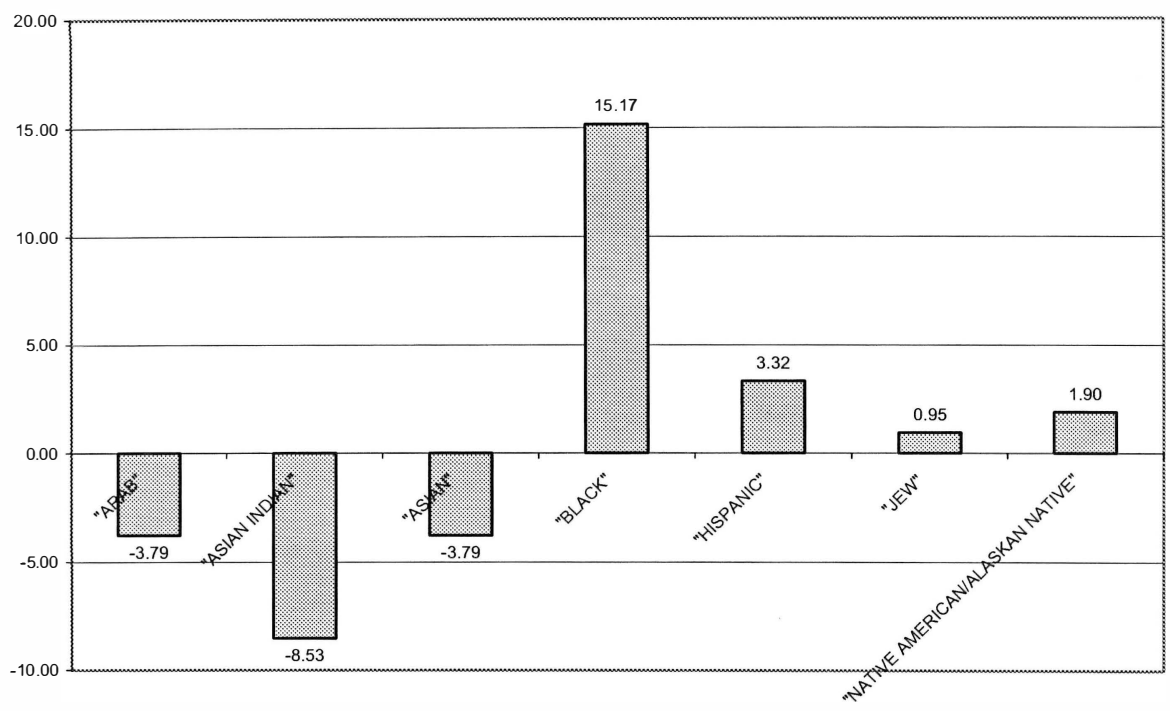

\section{Hypothesis Three}

The third hypothesis, "Respondents will be less inclined to indicate "I have no preference" in the permanent condition is supported. Figure 7 illustrates the percentages of respondents that indicated no preference for each condition.

Figure 7:

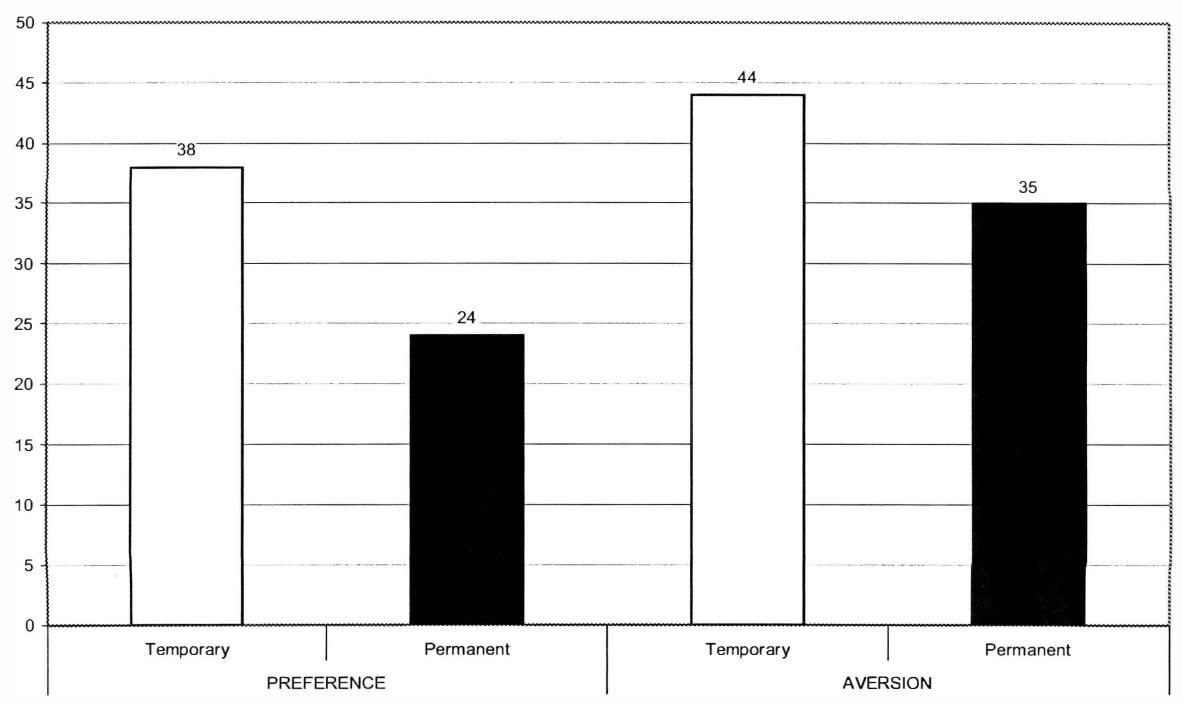


In order to test our third hypothesis, binomial tests were administered in SPSS.5 As indicated in Figure 7, respondents were more inclined to express some preference in the permanent rather than temporary conditions. The results were highly significant $(p<.001)$ in both the preference and aversion prompts. This indicates that the difference in the number of respondents selecting "no preference" in the temporary versus permanent conditions cannot be reasonably be attributed to chance. The third hypothesis is confirmed.

\section{Discussion}

In relation the hypotheses set forth above, contradictory results are apparent. At first glance, the results do not support the first and second hypotheses as Arab group membership is clearly the least preferred in both the temporary and permanent conditions and the most aversive in the temporary and permanent conditions. These results run counter to the assertion that a white-to-black continuum exists with blacks entrenched at the bottom. However, the emergent aversion to Arab is remarkable. Song (2004), for example, acknowledges that the attacks of September 11th have resulted in "heightened awareness of racial prejudice against people deemed Arab or Muslim," also asserting that "the evidence of 'Islamophobia' is not likely to challenge fundamentally... The widespread consensus is that there is a racial hierarchy in the USA, with whites at the top and African Americans at the bottom" (p.863). The results of this research suggest caution in adhering to such traditional notions of racial hierarchy in the United States and further, researchers should attend to the current experiences of people self-identified and ascribed as "Arab" to inform our understanding of race in the United States (see Anker, 2005; Domke, et al 2003; Witteborn 2004).

Despite the emergence of Arab aversion, our results indicate that the impact of shifting from temporary to permanent conditions in both the preference and aversion prompts appears to suggest support for blacks' bottom-rung position on a racial hierarchy. The difference between the selection of black group membership between the temporary and permanent conditions implies a cost associated with being permanently black that is more pronounced than any other group. Therefore, although Arab group membership is indeed the least preferred and most aversive selection, the notion of permanent blackness negatively impacts preference for black group membership. Indeed, black group membership is the only group selected with less frequency in the temporary versus permanent preference condition while also selected with more frequency in the permanent versus temporary aversion condition. This is only true with black group membership. Figure 8 is illustrative of this fact. 
Figure 8:

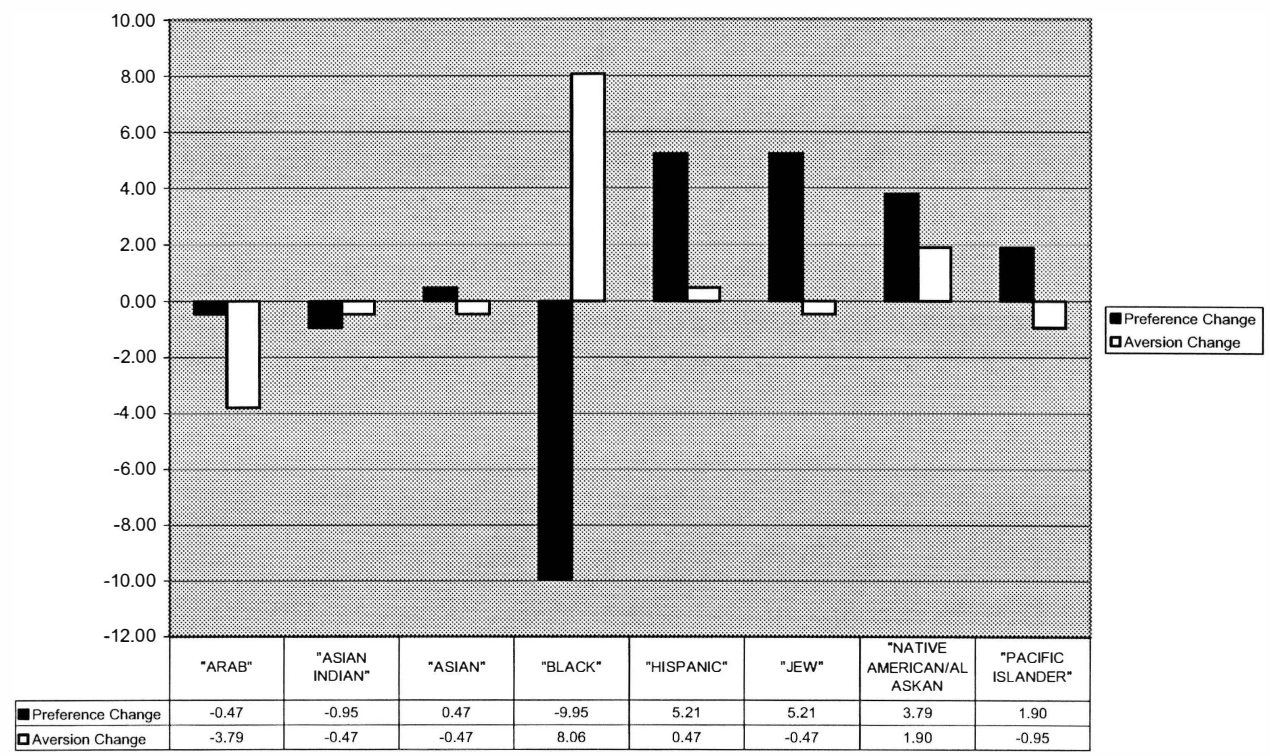

The strong preference for temporary Black group membership may be explained by what Cornell West calls the "Afro-Americanization of White youth" (1994, p. 121) and what Bill Yousman refers to as "Blackophilia" Yousman, 2003). The increasing popularity of hip hop music and hip hop culture provides White youth with an external point of reference with which they identify (Cutler 1999, Jones 1988, Kitwana 2005; Ledbetter, 1995). This is not a new phenomenon and extends back, perhaps, to the anthropological focus on people of color, the popularity of southern minstrelsy and even through to the fascination expressed in Norman Mailer's White Negro (1959). Considering the fact that the respondents are college-aged, it is most likely that hip hop music culture influences respondent willingness to be temporarily Black. Citing the longstanding fascination with Black culture, Tricia Rose asserts that:

Like generations of white teenagers before them, white teenage rap fans are listening in on black culture, fascinated by its differences, drawn in by mainstream social constructions of black culture as a forbidden narrative (1994, p.5).

Although the temporary preference is clear, it is also clear that the idea of permanent preference is unacceptable. This fascination dissipates in the face of permanence. 
Full consideration of the consistent preference for Pacific Islander membership and relative absence of expressed aversion to this membership extends beyond the limits of this analysis. However, the work of Edles (2004) and Desmond (1999) are useful as an initial point of reference for understanding this particular outcome. Edles critically examines the complex reality of race and ethnicity in Hawai' $i$. This reality stands in stark contrast to the myth of Hawai' $i$ as the "model minority state the state that "epitomizes" what a multiracial, multiethnic, multicultural "melting pot" should look like (p. 40, emphasis in original)." It is possible that an idealized conception of a multiracially harmonious Hawai'i influenced the respondents' preference for Pacific Islander group membership.

What may be a more likely influence is the continuing presentation of Hawai' $i$ that is "pictured" primarily as a tourist destination. Just as Edles presents the contradiction between the simplistic presentation of Hawai'i as a melting pot and the complex racial reality present there, Desmond presents a similar contradiction. In discussing the origins of tourism in Hawai'l, Desmond engages the contradiction between the presentation of Hawai' $i$ as a welcoming tourist paradise and the "strong anti-colonialist sentiments of some branches of today's Native Hawaiian Sovereignty Movement” (1999, p. 460). In the origins of Hawai'i's tourist industry

Native Hawaiians were seen as attractive, warm, welcoming, unthreatening, generous hosts. Importantly, Euramericans perceived them as "brown," not "black," "red," or "yellow," in the colorist terminologies of the day. For elite, white mainlanders Hawaiians seemed to offer and alluring encounter with paradisical exoticism, a nonthreatening soft primitivism primitive, yes, but delightfully so (pp. 40-461).

Perhaps the influence soft primitivism of tourist-driven marketing persists and has an impact on the selection of Pacific Islander group membership. Only additional research can effectively seek an answer to this question.

\section{Conclusion}

It is clear that both specific group membership and the permanence of group membership influence the selections of the respondents. This further challenges the notion of a colorblind society (see Brown et al, 2003 for an excellent critique of colorblindness). These respondents have constructed a coherent racial hierarchy where Arabs have emerged as a viable racial category and are situated at the bottom. Further, the idea of permanent blackness has particular negative salience. Ultimately, these results suggest that white students are aware of a racial hierarchy in American society and the potential costs and benefits of where one falls on this hierarchy. These two contested positions for Arabs and blacks 
at the bottom of the racial hierarchy would best be examined with additional research. More specifically, qualitative research will allow respondents to present more complete renderings of their ideas of racial hierarchy and racial meaning that are not directed by prescribed categories. Still, this research indicates that colorblindness is a myth for the respondents.

\section{Notes}

1 We do not mean to suggest that scholars conducting research on race and racial hierarchy (including ourselves) are unaware of its social construction. Rather, we simply attempt to acknowledge the persistent conceptual salience of race in research.

2 See Brown (1989) for a historical treatment of intermarriage and Ellinghuas (2002) for an excellent treatment of the dynamics of intermarriage in North America and Australia.

3 Two of the demographic questions on the survey were:

Being limited to the categories in TABLE 1, in which one of the above racial categories do people most often place you?

Being limited to the categories in TABLE 1, which one of the racial categories would you use to describe yourself?

In order to select respondents whose experience would be most characteristic of a "white" racial group, only those respondents selecting "white" for both questions were included.

4 According to the census, the prior minimum racial categories were American Indian or Alaskan Native, Asian or Pacific Islander, black, and white. In addition to two ethnicity categories: Hispanic origin and Not of Hispanic origin.. The current minimum racial categories are American Indian or Alaska Native; Asian; black or African America; Native Hawaiian or Other Pacific Islander; and white with two minimum categories for ethnicity: Hispanic or Latino and not Hispanic or Latino.

$5 \mathrm{~A}$ one-sample binomial test is a nonparametric test that allows us to determine whether or not two categorical dependent variables significantly differ from a hypothesized proportion. In this research, the hypothesized proportion is .50 which assumes that half of the respondents should indicate some preference and half should indicate "I have no preference." Significant results indicate a violation of this assumption. 


\section{References}

Almaguer, T. (1994). Racial Fault Lines: The Historical Origins of White Supremacy in California. Berkeley: University of California Press.

Anker, E. (2005). Villains, Victims and Heroes: Melodrama, Media, and

September 11. Journal of Communication, 55(1), 22-37.

Bashi, V. (1998). Racial categories matter because racial hierarchies matter: a commentary. Ethnic and Racial Studies, 21(5), 959-968.

Bashi, V., \& McDaniel, A. (1997). A Theory of immigration and racial stratification. Journal of Black Studies, 27(5), 668-682.

Bonilla-Silva, E. (2004). From Bi-racial to Tri-racial: Towards a New system of Racial Stratification in the USA. Ethnic and Racial Studies, 27(6), 931-950.

Brown, M., Carnoy, M., Currie, E., Duster, T., Oppenheimer, D., Shultz, M., et al. (2003). Whitewashing Race: The Myth of a Color-Blind Society. Berkeley, CA: University of California Press.

Brown, P. (1989). Black-White Interracial marriages: A Historical Analysis. The Journal of Intergroup Relations, 16(3 \& 4), 26-36.

Chae, H. S. (2004). Talking Back to the Asian Model Minority Discourse: Korean-origin Youth Experiences in High School. Journal of Intercultural Studies 25, no, 1, 59-73

Cutler, C. (1999). Yorkville Crossing: White teens, hip hop and African American English. Journal of Sociolinguistics, 3, 428-442.

Davis, F. (1991). Who is Black? One Nation's Definition. University Park, PA: Pennsylvania State University Press.

Davis, K. (1941). Intermarriage in Caste societies. American Anthropologist, 43, 376-395.

Desmond, J. (1999). Picturing Hawai' i: The "Ideal" Native and the Origins of Tourism, 1880-1915. Positions: East Asia Cultures Critique, 7(2), 459-501.

Domke, D., Garland, P., Billeaudeaux, A., \& Hutcheson, J. (2003). Insights Into U.S. Racial Hierarchy: Racial Profiling, News Sources, and September 11. Journal 
of Communication, 623.

Edles, L. (2004). Rethinking 'race', 'ethnicity' and 'culture': Is Hawai'i the 'model minority' state? Ethnic and Racial Studies 27, 1, 37-68

Ellinghaus, K. (2002). Margins of Acceptability: Class, Education, and Interracial Marriage in Australia and North America. Frontiers, 23(3), 55-75.

Feagin, J. (2001). Racist America: Roots, Current Realities and Future Reparations. New York: Routledge.

Forbes, J. (1990). The manipulation of race, caste, and identity. Journal of Ethnic Studies, 17, 1-51.

Fu, V. (2001). Racial Intermarriage Pairings. Demography, 38(3), 147-159.

Giroux, H. (1997). Rewriting the Discourse of Racial Identity: Towards a Pedagogy of Whiteness. Harvard Educational Review, 67, 285-320.

Gould, S. J. (1981). The Mismeasure of Man. New York: W.W. Norton.

Graves, J. (2003). The Emperor's New Clothes: Biologicall

Theories of Race at the Millenium. Rutgers, NJ: Rutgers University Press.

Graves, J. (2004). The Race Myth: Why We Pretend Race Exists in America. New York: Penguin Books.

Ho, P. (2003). Performing the "Oriental": Professionals and the Asian Model Minority Myth. Journal of Asian American Studies, 6(2), 149-175.

Ignatiev, N. (1995). How the Irish became white. New York: Routledge. Jones, S. (1988). Black Culture White Youth. Basingstoke: Macmillan.

Kalmijn, M. (1998). Intermarriage and Homogamy: Causes, Patterns, and Trends. Annual Review of Sociology, 24, 395-421.

Kibria, N. (1996). Not Asian, Black or white? Reflections on South Asian American racial identity. Amerasia Journal, 22(2), 77-86.

Kibria, N. (1998). The contested meanings of 'Asian American': racial dilemmas in the contemporary US. Ethnic and Racial Studies, 21(5), 939-958.

Kitwana, B. (2005). Why White Kids Love Hip-Hop: Wangstas, Wiggers, Wannabes, and the New Reality of Race in America. New York: Basic Civitas 
Books.

Lacy, K. (2004). Black Spaces, Black places: Strategic Assimilation and Identity Construction in Middle-class Suburbia. Ethnic and Racial Studies, 27(6), 908-930.

Ledbetter, J. (1995). Imitation of Life. In G. Dines \& J. Humez (Eds.), Gender, race and class in media (pp. 540-544). Thousand Oaks, CA: Sage.

Lee, S. J. (1994). Behind the Model-Minority Stereotype: Voices of High- and Low-Achieving Asian American Students. Anthropology and Education Quarterly, 25(4), 413-425.

Lewandowski, D., \& Jackson, L. (2001). Perceptions of Interracial Couples:

Prejudice at the Dyadic Level. Journal of Black Studies, 27(288-303).

Lipsitz, G. (1998). The Possesive Investment in Whiteness: How White People Profit from Identity Politics. Philadelphia: Temple University Press.

Lopez, I. H. (1995). White by law. In R. Delgado \& J. Stefancic (Eds.), Critical Race Theory: The Cutting Edge. Philadelphia: Temple University Press.

Mailer, N. (1959). The White Negro. In Advertisements for myself.

New York: Putnam.

Min, P. G. (1999). Major Issues Relating to Asian American Experieces. In F. Pincus \& H. Ehrlich (Eds.), Race and Ethnic Conflict: Contending Views on Prejudice, Discrimination, and Ethnoviolence. Boulder, Colorado: Westview Press. Montague, A. (1997). Man's Most Dangerous Myth: The Fallacy of Race. New York: Columbia University Press.

Morning, A. (2001). The Racial Self-identification of South Asians in the United States. Journal of Ethnic and Migration Studies, 27(1), 61-29.

Nagel, J. (1986). The Political Construction of Ethnicity. In S. Olzak \& J. Nagel (Eds.), Competitive Ethnic Relations. San Diego: Academic Press.

Nagel, J. (1994). Constructing Ethnicity: Creating and Recreating Ethnic Identity and Culture. Social Problems, 41(1), 152-176.

Niven, D., \& Zilber, J. (2000). Elite Use of Racial Labels: Ideology and 
Preference for African American or Black. Howard Journal of Communications, 11, 267-277.

Porterfield, E. (1978). Black and White Marriages. Chicago: Nelson-Hall.

Porterfield, E. (1982). Black American Intermarriage in the in the United States. Marriage and the Family Review, 5, 14-34.

Prashad, V. (2000). The Karma of Brown Folk. Minneapolis, MN: University of Minnesota Press.

Qian, Z. (1997). Breaking the Racial Barriers: Variations in Interracial Marriage between 1980 and 1990. Demography, 34, 263-276.

Roediger, D. (1994). Towards the Abolition of Whiteness. London: Verso Press. Rose, T. (1994). Black Noise: Rap Music and Black Culture in Comtemporary America. Hanover, New Hampshire: Wesley University Press.

Sidanius, J. (1993). The psychology of group conict and the dynamics of oppression: a social dominance perspective. In S. lyengar \& W. McGuire (Eds.), Explorations in Political Psychology.

Durham, NC: Duke Univeristy Press.

Sidanius, J., \& Pratto, F. (2001). Social Dominance: An Intergroup Theory of Social Hierarchy and Oppression Cambridge: Cambridge University Press. Tuan, M. (1998). Unraveling the "Model Minority" Stereotype: Listening to Asian American Youth. Journal of Asian American Studies 1, no, 2, 198-201. Yamato, A. (1999). The Contemporary Asian American Experience: Beyond the Model Minority. Journal of Asian American Studies 2, no, 2, 221-222. 